\title{
Is it always Slowdown of the Walker circulation at solar cycle maximum?
}

Indrani Roy

IRDR, University College London (UCL); email: Indrani.roy@ucl.ac.uk

This is a Post-Print of a Short Communication published in Natural Hazards, Springer Nature, 17 March 2021 Published DOI: https://doi.org/10.1007/s11069-021-04653-5

\begin{abstract}
.
It is a commentary following a published paper in PNAS titled, 'Slowdown of the Walker circulation at solar cycle maximum', by Stergios Misios et al (2019). The article of Misios et.al.(2019) claims that there is a slowdown of the Walker Circulation during maximum periods of solar cycles. In support, they provided model results. They also gave directions of improved future predictive skill involving that knowledge of solar cycles. However, their work does not comply with various observational results. This contribution highlights those areas and pinpoints discrepancies. Knowing the limitations of models, if any model results match some very limited part of observations, it is not possible to make similar claims. It raises doubt on any improvement of future predictive skill.
\end{abstract}

\section{Introduction.}

The area of Sun-ENSO connection is one of the major disputed topics in recent periods (Roy, 2010; Roy and Haigh, 2012; Roy, 2014; van Loon et al, 2007; White et al 1997; Roy 2018a). That subject became more important and deserved more attention due to current global warming scenarios. The sun (represented by SunSpot Number (SSN)) and ENSO connection-contradiction and possible reconciliation were addressed extensively by previous studies (Roy 2018a; Roy, 2014). Those elaborately discussed contradictory findings (van Loon et al, 2007; White et al 1997). Solar related possible mechanisms, around the tropical Pacific, which is different in earlier and later periods are also hypothesized (Roy, 2014; Roy, 2020, Fig.3 (preprint version 2016)) considering both the atmosphere-ocean feedback. Further to clarify the result of observation, two different segments of periods are discussed here in terms of SSN-ENSO behaviour considering the last 160 years. 


\section{i) High solar years show cooling in central tropical Pacific before 1957 and after}

1998: During that period, high solar years those include peak (or max) solar years, 1-year lag and 2-year lag, all are dominated by the cold event(C) of ENSO (Table-1). Warm ENSO years(W) in Table 1 for either peak or 1 to 2-year lag if noticed, they occur only when solar cycles are weak and SSN is sufficiently low (seen in Fig.1). The threshold of SSN marking high solar years are shown by a horizontal dotted line in Fig.1.

ii) Intervening Period of 1958 to 1997: In Table 1, the horizontal dashed lines indicate a period separated based on slowing down of the strength of shallow oceanic Meridional Overturning Circulation in tropical Pacific (McPhaden and Zhang, 2004); weakening of both the Hadley and Walker cell (more for Walker cell) (Vecchi, G.A. and Soden, B. J., 2007; Roy 2014). Solar max or peak years are dominated by cold events(C) of ENSO (Table 1). For all solar cycles, it is warm ENSO (W) in one-year lag. In Fig. 1 also, either using SSN version 1 or 2, solar peak or max (red squares) are still biased towards cold ENSO. Other high solar years (above threshold), however, do not show any preferences, towards cold events, like the earlier period.

Throughout the overall 15 solar cycles, a total of 12 out of 15 solar max years lie on the cold ENSO side (Fig 1, red squares). That is the reason, studies those focused only on peak or max solar years (van Loon et al (2007)) observed a very significant cooling around tropical Pacific for 150 years and indicated a strengthening of Pacific Walker Circulation (PWC). Fig. 1 and Table 1 focuses Dec-Jan-Feb (DJF), because ENSO amplitude peaks at northern winter and hence the connection between SSN and ENSO(if any), should be better captured.

Studies for decadal time scale solar signal after filtering out ENSO, Volcano, trend was also done previously using observation and applying Multiple Linear Regression (MLR) techniques (Gray et al., 2013; Roy and Haigh, 2010; Roy, 2014). Study finds very nominal warming for SSN in central Pacific for 155 years period (Roy and Haigh, 2010, their Fig. 2a). One co-author of Misios et.al. (2019) earlier also showed a solar decadal response in HadISST Sea Surface Temperature (SST) data for 1870-2010 (Gray et al. (2013), Fig 5). That covered zero-lag as well as 1 year-lag to 3 year-lag. Solar signal suggested significant negative SST variation in Nino 1+2, and Nino 3 region. Consistent to the previous study (Roy and Haigh, 2010) the signal in the Nino3.4 region is near neutral. Using similar MLR technique Roy, $(2014$, their Fig. 11, 12) also analysed solar signal on tropical Pacific SST. Their Fig. 11 suggests solar decadal signal is nominal in tropical Pacific. In MLR, it does not change with or without ENSO during 1856-1957, but during the intervening period of 1958-1997, the situation is different. If ENSO is not taken into account in MLR, it shows 
warming, but if ENSO is excluded it shows nominal signal. Thus during 1958-1997, the ENSO is mixed up with solar signal (Roy, 2010).

During the intervening period of 1958-1997, there was a decrease in Pacific Walker Circulation (PWC), but the strength has again increased since 1998 (Vecchi and Soden, 2007). The same is also true for other tropical Pacific oceanic features linked to PWC (McPhaden and Zhang, (2004)). Since 1998, high SSN suggests cold ENSO (Fig.1, Table-1) and thus strengthening effect on PWC. In spite of a significant increase of GHG since 1998, there is a strengthening of PWC as noted in many observational results (McGregor et al. 2014, among others). Thus, increased GHG also caused a strengthening of PWC since 1998, without even considering any SSN (McGregor et al. 2014). These discussions suggest the last sentence of abstract is not correct which is: 'Demonstration of this mechanism acting on the 11-y SC timescale adds confidence in model predictions that the same mechanism also weakens the PWC under increasing greenhouse gas forcing.'

The study of Misios et.al.(2019) only matches with the work of White et al. (1997) that focused the period of latter half of the twentieth century and found warming in tropical Pacific with high SSN. However, the proposed mechanism involving ITCZ and SLP in central Pacific also does not agree with observation during that period. Solar signals in observed Sea Level Pressure (SLP) around central tropical Pacific is studied using MLR technique segregating ENSO, volcano and trend. SLP around central Pacific which may influence ITCZ is seen to strengthen PWC ((Roy and Haigh, 2010, their Fig. 1; Gray et al. 2013, Fig. 4), and not weakens and hence wrong referencing. Such intensification of SLP around ITCZ, central Pacific, is also present in observational record of one-year lag for 150 years record (Roy (2020), Fig6a (preprint version 2016); Gray et al. 2013, Fig. 4). However, it is sensitive to the time period chosen (earlier or later). Interestingly, though earlier period suggests strengthening of ITCZ, the later period indicates an insignificant influence of the SSN on tropical Pacific SLP (Roy 2020, Fig6a (preprint version 2016)). It is true for one-year lag as well as zero lag. Hence also the question arises based on their proposed mechanism (Misios et.al., 2019) involving SLP and weakening of ITCZ, even during that period.

It is worth mentioning that Hydrology cycle around the tropical Pacific, the strength of Walker circulation and tropical Pacific Nino SST all are coupled and linked together. Those are not isolated features. In terms of Solar ENSO connection, models are likely to give varied behaviours. Some will show warming, some will show cooling, and some will indicate neutral and we are aware of limitations of models. Thus, if any model results match some part of 
observation for only three solar cycles, it is not possible to state 'SC forcing is a source of skill for decadal predictions in the Indo-Pacific region' and similar arguments. Solar related different mechanisms around the tropical Pacific were also hypothesized in some earlier studies (Roy, 2014; Roy 2020 ( preprint version 2016)). Those considered both the atmosphere-ocean feedback and separated out an intervening period (1958-1997) from the last 165 years period. Those could be further tested using idealised forcing.

Acknowledgement. This study did not receive ant funding.

Conflict of Interest: There is no conflict of interest.

\section{References}

Gray, L. J., A. A. Scaife, D. M. Mitchell, S. Osprey, S. Ineson, S. Hardiman, N. Butchart, J. Knight, R. Sutton, and K. Kodera (2013), A lagged response to the 11 year solar cycle in observed winter Atlantic/European weather patterns, J. Geophys. Res. Atmos.,118, 13,40513,420, doi:10.1002/2013JD020062.

McPhaden, M. J, and Zhang, D., (2004): Pacific Ocean circulation rebounds, Geophys. Res. Lett., 31, L18301, doi:10.1029/2004GL020727.

McGregor S et al. (2014) Recent Walker circulation strengthening and Pacific cooling amplified by Atlantic warming. Nat. Clim. Change, 4, 888-892.

Misios et al. (2019) Slowdown of the Walker circulation at solar cycle maximum, PNAS, 116 (15) 7186-7191.

Roy, I. and Haigh, J.D., (2012), 'Solar Cycle Signals in the Pacific and the Issue of Timings, Journal of the Atmospheric Sciences, 2012, 69, 4, 1446-1451.

Roy, I, (2010), 'Solar signals in sea level pressure and sea surface temperature'. PhD thesis, Department of Space and Atmospheric Science, Imperial College, London, https://doi.org/10.25560/6038

Roy I (2014) The role of the sun in atmosphere-ocean coupling, International Journal of Climatology, 34 (3), 655-677, doi:10.1002/joc.3713. 
Roy I., (2020), 'Major climate variability and Natural factors in Boreal Winter' Pure and Applied Geophysics. https://doi.org/10.1007/s00024-020-02522-z, Preprints 2016, 2016080025 (doi: 10.20944/preprints201608.0025.v2).

Roy I (2018a) Climate Variability and Sunspot Activity - Analysis of the Solar Influence on Climate, publisher Springer Nature, 18 chapters, 216 pages, ISBN 978-3-319-77107-6, DOI: 10.1007/978-3-319-77107-6.

Roy, I, (2018b), 'Addressing on abrupt global warming, warming trend slowdown and related features in recent decades' Frontiers, 6,136, DOI: 10.3389/feart.2018.00136, URL:https://www.frontiersin.org/article/10.3389/feart.2018.00136

Roy I and Haigh JD (2010) Solar cycle signals in sea level pressure and sea surface temperature, Atmospheric Chemistry and Physics (ACP), 10, 6, 3147-3153.

Stergios Misios, Lesley J. Gray, Mads F. Knudsen, Christoffer Karoff, Hauke Schmidt, and Joanna D. Haigh, (2019), Slowdown of the Walker circulation at solar cycle maximum, PNAS, 116 (15) 7186-7191.

van Loon H, Meehl GA, and Shea DJ (2007) Coupled air-sea response to solar forcing in the Pacific region during northern winter. J Geophys. Res.-Atmos., 112, D02108, doi: 10.1029/2006JD007378.

Vecchi, G.A. and Soden, B. J., (2007): Global Warming and the Weakening of the Tropical Circulation, J. Climate., 20, 4316-4340.

White WB, Lean J, Cayan DR et al. (1997) Response of global upper ocean temperature to changing solar irradiance. J. Geophys. Res.-Oceans, 102(C2), 3255-3266. 
Figure Legend:

Fig. 1. Average ENSO (DJF) (measured in terms of Nino3.4) against annual average Sunspot number (SSN): a) uses SSN version 1 for 1856-2015 and bottom panel separates period 1958-1997 (Roy, 2020, their Fig. 4); b) uses SSN version 2 for 1856-2016 and right panel segregates period 1958-1997 from the rest (Roy, 2018b, their Fig. 10B). For Fig. 1a (top) and Fig. 1b (left), all points above horizontal dotted line, i.e., when SSN is sufficiently high, lie on the cold event (C) side of ENSO. Those include solar max year, 1-year lag and 2-year lag. A threshold of SSN, above which, it is always cold ENSO, is 80 for SSN version 1 (Fig. 1a, top), while 120 for SSN version 2 (Fig. 1b, left). The rest two plots for the intervening period (1958-1997) do not show any such bias for high SSN (above threshold).

\section{Table Legend:}

Table 1 The ENSO (DJF) value at the year of peak SSN (using version 1), and the following two years, during 1856-2007. 'C/W' indicate that the ENSO 3.4 index is 0.02 units lower/higher than its average value, while '-' indicates a near neutral state (Roy and Haigh, 2012, their Table 1). The horizontal dashed lines indicate a period separated based on weakening of both the Hadley and Walker cell (more for Walker cell). Over the 'Total' period (bottom row), peak year, 1-year lag and 2-year lag all are outnumbered by 'C' [Source: Roy and Haigh, 2012]. 
a)

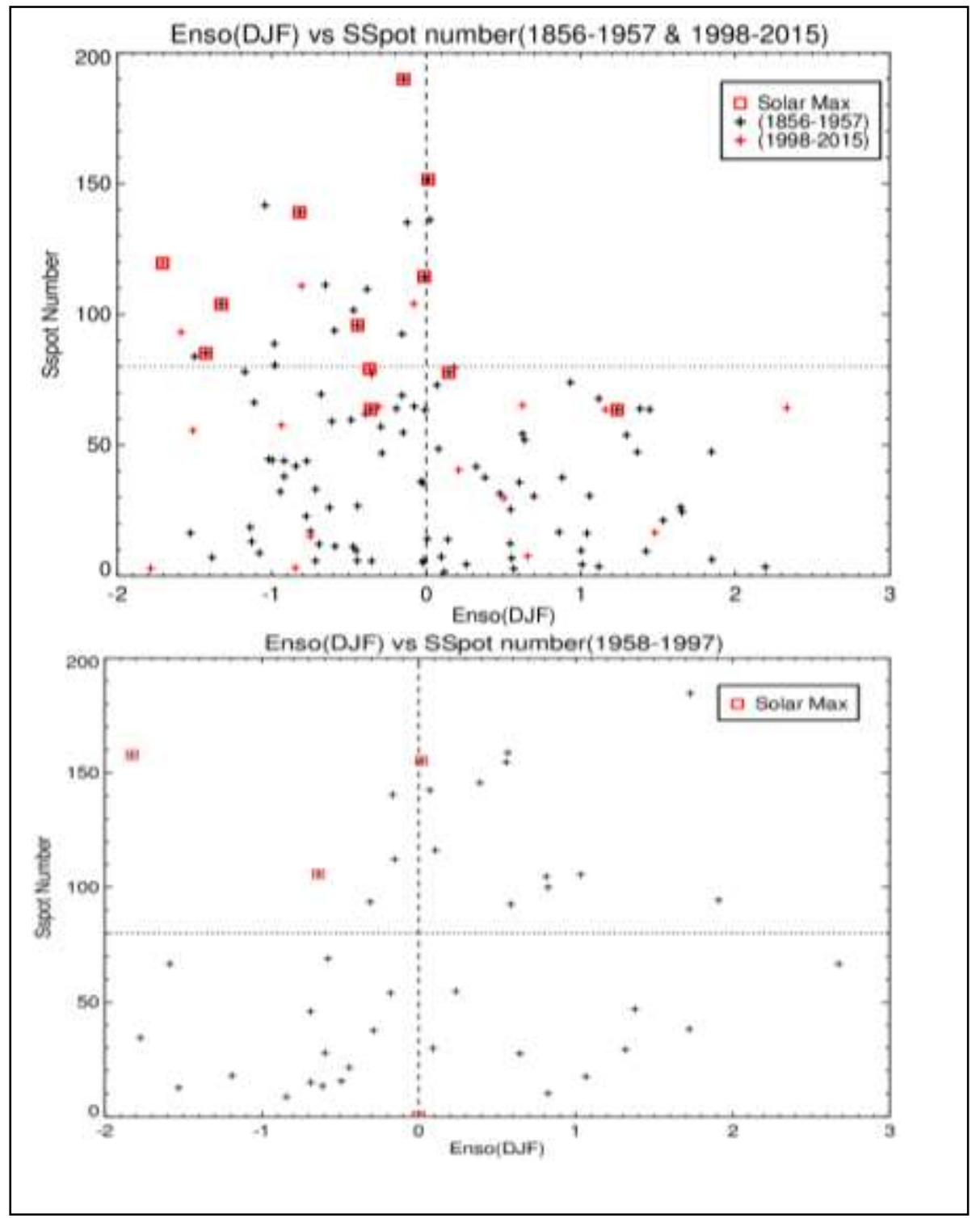

b)

Observation: Enso(DJF) vs SSN:(1856-1957 \& 1998-2016

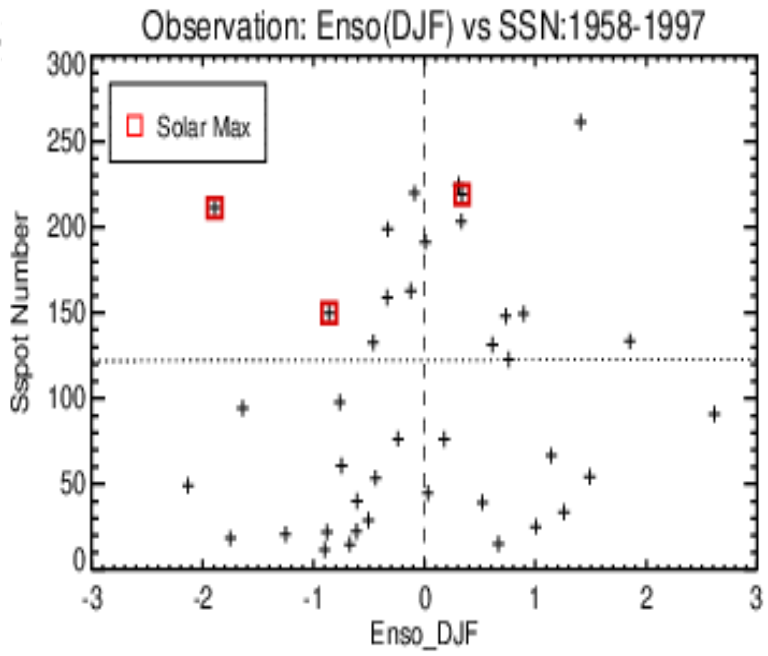


Fig. 1. Average ENSO (DJF) (measured in terms of Nino3.4) against annual average Sunspot number (SSN): a) uses SSN version 1 for 1856-2015 and bottom panel separates period 1958-1997 (Roy, 2020, their Fig. 4); b) uses SSN version 2 for 1856-2016 and right panel segregates period 1958-1997 from the rest (Roy, 2018b, their Fig. 10B). For Fig. 1a (top) and Fig. 1b (left), all points above horizontal dotted line, i.e., when SSN is sufficiently high, lie on the cold event $(C)$ side of ENSO. Those include solar max year, 1-year lag and 2-year lag. A threshold of SSN, above which, it is always cold ENSO, is 80 for SSN version 1 (Fig. 1a, top), while 120 for SSN version 2 (Fig. 1b, left). The rest two plots for the intervening period (1958-1997) do not show any such bias for high SSN (above threshold). 
Table 1 The ENSO (DJF) value at the year of peak SSN (using version 1), and the following two years, during 1856-2007. 'C/W' indicate that the ENSO 3.4 index is 0.02 units lower/higher than its average value, while '-' indicates a near neutral state (Roy and Haigh, 2012, their Table 1). The horizontal dashed lines indicate a period separated based on weakening of both the Hadley and Walker cell (more for Walker cell). Over the 'Total' period (bottom row), peak year, 1-year lag and 2-year lag all are outnumbered by ' $\mathrm{C}$ '.

[Source Roy and Haigh, 2012].

\begin{tabular}{|c|c|c|c|c|c|}
\hline Solar & Years & Peak Year & & of ENSO & \\
\hline $\begin{array}{l}\text { Cycle } \\
\text { no }\end{array}$ & & & $\begin{array}{l}\text { peak } \\
\text { year }\end{array}$ & $\begin{array}{r}1 \text { y after } \\
\text { peak y }\end{array}$ & $\begin{array}{r}2 \text { y after } \\
\text { peak y }\end{array}$ \\
\hline 10 & $1856-1867$ & 1860 & $C$ & $\mathrm{C}$ & C \\
\hline 11 & $1867-1878$ & 1870 & $\mathrm{C}$ & $\mathrm{C}$ & $\mathrm{C}$ \\
\hline 12 & $1878-1890$ & 1883 & C & - & W \\
\hline 13 & $1890-1901$ & 1893 & C & C & C \\
\hline 14 & $1901-1913$ & 1905 & W & W & C \\
\hline 15 & $1913-1923$ & 1917 & C & C & W \\
\hline 16 & $1923-1933$ & 1928 & W & C & W \\
\hline 17 & $1934-1944$ & 1937 & - & $\mathrm{C}$ & C \\
\hline 18 & 1944-1954 & 1947 & - & W & C \\
\hline 19 & 1955-1964 & 1957 & $\mathrm{C}$ & W & W \\
\hline 20 & 1964-1976 & 1968 & C & W & W \\
\hline 21 & $1976-1986$ & 1979 & - & W & C \\
\hline 22 & 1986-1996 & 1989 & C & W & W \\
\hline 23 & $1996-2007$ & 2000 & $\mathrm{C}$ & $\mathrm{C}$ & $\mathrm{C}$ \\
\hline & Total & & $\begin{array}{l}9 \mathrm{C} \\
3- \\
2 \mathrm{~W}\end{array}$ & $\begin{array}{l}7 \mathrm{C} \\
1- \\
6 \mathrm{~W}\end{array}$ & $\begin{array}{l}8 \mathrm{C} \\
0- \\
6 \mathrm{~W}\end{array}$ \\
\hline
\end{tabular}

